\title{
Filosofía práctica. Una antigua y nueva forma de hacer filosofía
}

\section{Practical philosophy. An ancient and new way of doing philosophy}

Dr. Francisco Castillo Ávila ${ }^{1}$

\begin{abstract}
Resumen:
La filosofía en tanto ejercicio sistemático del pensamiento ha sido entendida de diferentes formas a través de la historia. El presente artículo examina las diversas maneras de concebir la filosofía. Así como la ciencia se divide en ciencia teórica y ciencia práctica, la filosofía también puede ocupar esta división, es decir, teórica o especulativa y filosofía práctica o sapiencial. La filosofía teórica, propia de la academia y los especialistas, comienza con el estudio riguroso y sistemático de las obras de los grandes filósofos, de sus discípulos y críticos; en cambio, la filosofía práctica se inicia con el lema "conócete a ti mismo". Esta última trata de resolver los problemas cotidianos de las personas con filosofía, ocupando el pensamiento de los filósofos y pensadores de todos los tiempos. A fines del siglo XX surge dentro de la filosofía práctica, lo que se ha denominado asesoramiento filosófico o consejería filosófica o terapia filosófica que tiene como objetivo ayudar a las personas o grupos a resolver o enfrentar situaciones existenciales a partir de los pensamientos de los filósofos.
\end{abstract}

Palabras clave: Filosofía - filosofía práctica - asesoramiento filosófico asesor filosófico.

\begin{abstract}
:
Philosophy, due to several systematic practice of thinking, has been understood in different ways through history. The present paper examines diverse forms of philosophy conception. As the science is divided in theoretical and practical; philosophy also may use this classification, i.e. theoretical or speculative and practical or sapiental philosophy. Theoretical philosophy, proper to the academy and specialists starts the exhaustive and systematic study of great thinkers, their disciples and
\end{abstract}

\footnotetext{
1 Profesor de Castellano y Filosofía por la Universidad Austral de Chile, Diploma en Ciencias de la Religión, mención Cristianismo por la Universidad de Chile, Magíster Artium en Filosofía con especialidad en Filosofía de las Ciencias por la Universidad de Santiago de Chile, Doctor en Filosofía con mención en Ética por la Universidad de Chile. Académico permanente de la Universidad Católica Silva Henríquez. Contacto: franciscus7@hotmail.com
} 
their critics work. Instead, practical philosophy begins with the motto "know yourself". This one intends to solve common problems of people with philosophy, using thoughts of philosophers and thinkers of all times. In late XX century emerged within the practical philosophy, which has been called philosophic consulting, advicing or therapy that has as objective to help people or groups to solve or face existential situations from philosophers thinking.

Key words: Philosophy - practical philosophy - philosophic consulting - philosophic consult

\section{Concepciones de la filosofía}

La filosofía a través de la historia se ha definido de tantas maneras como filósofos han existido. Sin embargo, todas las formas de concebirla, por ejemplo: la filosofía como concepción del yo, la filosofía como concepción del universo, la filosofía como ciencia, la filosofía como aspiración a la virtud, etc., apuntan a dos rasgos comunes, a pesar de todas las diferencias que presentan. Son " $1^{\circ}$ la orientación hacia la totalidad de los objetos; $2^{\circ}$ el carácter racional, cognoscente de esta orientación" ${ }^{\prime 2}$. En efecto, en todas ellas encontramos una tendencia a la universalidad, una orientación hacia la totalidad de los objetos, o sea el carácter de universalidad es propio de la filosofía; y en segundo lugar: "la actitud del filósofo ante la totalidad de los objetos es una actitud intelectual, una actitud del pensamiento. El filósofo trata de conocer, de saber." ${ }^{3}$ El filósofo está en busca de una sabiduría racional dirigida a las grandes interrogantes de la existencia.

La filosofía, tanto por su nombre como por sus contenidos y problemas, es una invención de los griegos. Por su nombre, significa amor (philia) a la sabiduría (sophía); y por tanto en una primera aproximación se denominará filósofo: el amante de la sabiduría. Sin embargo, hay amor a los hombres, a las mujeres, a los padres, a las riquezas, al arte, a Dios; por tanto ¿en qué consistirá este curioso amor que se

\footnotetext{
2 HESSEN, J. Teoría del Conocimiento. Editorial Losada, 1967, Pág. 13.
}

3 Ibídem. 
llama, desde los tiempos de los griegos, amor a la sabiduría? Tenemos que decir que el amor a la sabiduría propio de los filósofos es una unidad extraña, un todo especial, que a lo largo de la historia se ha concretizado en muchos pensadores amantes de la sabiduría, pero cada uno ha amado a la sabiduría a su modo, y además, cada uno también ha amado un aspecto especial favorito. Además, la palabra "filosofía" podemos darla vuelta en sofía-filo, o sea una sabiduría sobre el amor, un saber racional acerca del amor, de la amistad, del cuidado y conocimiento de sí: de la autognosis. Luego, la historia de estos tipos de amor es la historia íntima de la Filosofía, la cual repasaremos brevemente. Por tanto, aquí el término amor podemos reemplazarlo por pensamiento dedicado $a$.

\section{La filosofía como amor a la sabiduría de la contemplación}

En la antigua Grecia, la Filosofía era entendida como amor a la contemplación. Los filósofos eran hombres dedicados a la contemplación. La actitud más común de los seres humanos no es, por cierto, la de mirar pura y simplemente. En general, somos amigos de poseer, dominar, servirnos de las cosas, gastarlas y consumirlas según nuestros propios apetitos y gustos, transformándolos para nuestra conveniencia. No basta con ver, sino se quiere tener. Así la actitud práctica es la que predomina en el ser humano. Ser filósofo, en cambio, es colocarse ante todo en otra actitud: esencialmente contemplativa, especulativa, un profundo y desinteresado mirar las cosas, ver lo que son en sí mismas, sírvannos o no, valgan o no valgan para algo. Platón en su diálogo La República (457) señala que el filósofo genuino y auténtico es el amante de contemplar la verdad, amigo de mirar. Más adelante, en el mismo diálogo (480 a) dice que se ha de llamar filósofos a los que son capaces de abrazar, de dar la bienvenida a todos los seres, y a besar en cada uno de ellos lo que tengan de inmutable, de eterno, de siempre idéntico (484 b). Luego, según Platón un filósofo es amante de mirar, no es hombre de acción, no se propone transformar las cosas, sino sólo verlas, ver lo que ellas nos presentan. La Verdad significaba para el griego clásico lo mismo que estar descubierto, no tener velos. Por 
tanto, el filósofo es amante de la verdad, de ver lo que las cosas nos manifiestan. El filósofo es la persona que intenta ver íntegramente e íntimamente las cosas, su ser profundo. Por el contrario, el hombre común, precisamente por su afán de servirse de ellas, de utilizarlas, no ve lo que son y sólo sabe aprovechar lo más externo y superficial. El filósofo, en cambio, se propone, pues, conocer las ideas de las cosas, no sus utilidades o valores prácticos. Desea saber qué son, y no para qué sirven al ser humano. A esta actitud contemplativa también se le llama especulativa, propósito teórico, hacer teoría de las cosas. El filósofo pretende conocer las ideas de las cosas. A este conocimiento, podrá seguir o no la acción; pero al filósofo como tal, no le interesa primeramente la acción.

Pero además de la contemplación, lo propio de la filosofía es su universalidad. En efecto, como dice Platón, el filósofo le da la bienvenida a todos los seres. Esto significa acogerlos con interés, enterarnos de qué se componen, cuáles son sus relaciones, qué es lo que nos enseñan, investigar su idea. Este deber de universalidad no le interesa al hombre común, preocupado por algunas cosas, las que le sirven a las faenas cotidianas, del día a día. En este sentido, el filósofo es capaz de abstraerse, ensimismarse, alejarse del mundo concreto. Piénsese en la escultura el Pensador de Rodin, absorto en su meditación.

Además de la contemplación y de la universalidad, lo propio del filósofo es buscar lo inmutable, lo permanente. En efecto, todo lo que acontece está sometido al cambio: cosas, sentimientos, personas, acciones, etc. ¿Acaso hay algo permanente?; ¿qué es lo eterno de las cosas? Según Platón es su idea, su esencia, su definición, el logos. Todos los hombres son mortales, nacen y mueren, pero los que nacen como aquellos que mueren son hombres por igual, es decir son animales racionales. Esa cualidad es la esencia del hombre, no cambia jamás, aunque cada uno de los individuos cambien y fallezcan. Por su parte, el discípulo más grande de Platón, Aristóteles, seguirá en la línea de que la filosofía es contemplación. Todos los hombres tienen apetito de saber, comienza diciendo en su Metafísica, y a esta palabra saber corresponde en griego ver ideas, esencias. La filosofía emerge cuando 
el ser humano está en estado de ocio, liberado de las ocupaciones cotidianas. La filosofía es teoría, conocimiento de las causas de las cosas. Aristóteles escribe: "todos concuerdan que la sabiduría, propiamente dicha, concierne a las primeras causas y primeros principios. Y si, como se dijo, el empírico parece más sabio del que tiene de los entes puras sensaciones: y más sabio que el empírico aparece el que posee el arte -y el técnico más que el artesano- ¡cuánto no será superior la ciencia puramente especulativa a la que tiene por fin la producción" (Metafísica 1.980 a). Y en otro párrafo se refiere a la inutilidad de la filosofía, en cuanto saber contemplativo: "De lo que queda dicho resulta claro que la sabiduría es la ciencia e intuición (visión) de las cosas más excelsas por naturaleza. Y así de Anaxágoras y Tales y de sus semejantes se dice que son sabios y no prudentes, pues los vemos ignorantes de las cosas que les son provechosas, reconociéndose, en cambio, que saben de cosas superiores y maravillosas y arduas y divinas, bien que sean inútiles, puesto que no son los bienes humanos lo que ellos buscan". (Ética, VI, 7)

\section{- La filosofía como amor a la sabiduría de la acción}

Aquí la filosofía va a dejar de ser una sabiduría erudita para transformarse en un saber de salvación, de orientación en el mundo. Los filósofos han hablado mucho, han gastado las palabras, los conceptos. Ahora el ideal de vida es el silencio y/o la acción. Se reemplaza la palabra, el logos, por una actitud ejemplar o el hecho anecdótico ${ }^{4}$. Para estos filósofos (Filosofía Helenístico-Romana: Cicerón, Epicuro, Marco Aurelio, etc.), conocer ya no será como entre los griegos clásicos, mirar, contemplar, especular, sino obrar, aprehender, captar, capturar para sí. El conocer tiene que ser y terminar en acción que capte, que se posesione del objeto conocido. La Filosofía estudiará las ideas en cuanto sean instrumentos de acción. Aquí la filosofía le dio mas importancia a

4 Véase OYARZúN, Pablo. El dedo de Diógenes. La anécdota en Filosofía. Dolmen Ediciones, Stgo, 1996. 
las virtudes, pues éstas son principios de acción, causas reales por las que nos transformamos a nosotros mismos realmente. Aquí surgen las grandes escuelas éticas como el estoicismo y el epicureísmo. Marco Aurelio escribe: "El tiempo de la vida humana es un punto... todas las cosas del cuerpo son a manera de un río; las del alma sueño y vaho; la vida, una lucha, un destierro, la fama de la posteridad, olvido. ¿Qué hay, pues, que nos pueda llevar a salvamento? Una sola y única cosa: la filosofía". 5 Por su parte Epicuro también motiva a sus discípulos a dedicarse a la filosofía: "Nadie por ser joven dude en filosofar ni por ser viejo de filosofar se hastíe. Pues nadie es joven o viejo para la salud de su alma... Necesario es, pues, meditar lo que procura la felicidad, si cuando está presente todo lo tenemos y, cuando nos falta, todo lo hacemos por poseerla". ${ }^{6}$

Estas dos concepciones de la filosofía, tanto como contemplación y, la otra, como acción, nos servirán más adelante al distinguir dos grandes tipos: filosofía teórica y filosofía práctica. Luego, ya están puestas las bases para entenderla de dos formas diferentes pero complementarias.

\section{La filosofía como amor a la sabiduría divina (Dios)}

Siguiendo la historia nos encontramos con la filosofía entendida como amor a Dios. En efecto, en la Edad Media, entre los siglos IV y XIV, la filosofía en Occidente fundamentalmente se convierte en esclava de la teología; es la filosofía cristiana. Aquí los grandes pensadores: Agustín, Tomás de Aquino, filosofan al servicio de Dios y de lo que Dios ha revelado a los hombres siguiendo los textos sagrados: los dos Testamentos. "Se puede afirmar que el pensamiento cristiano medieval se va destilando en la paciente y humilde tarea de 'hacer hablar' al texto sagrado en el que está contenida, para sus investigadores, toda la verdad que podía interesar al hombre." (Giannini, Breve Historia de 
la Filosofía, p. 99). Filosofar es, en la época medieval, ver en todo la huella, la imagen de Dios, saber cómo todo depende y proviene de Él, cómo todo va a Él, siendo causa final y eficiente de todo. Luego, no se puede filosofar sin amor a Dios. Dios es la Sabiduría viviente, personal y omnipotente a la vez, objeto de contemplación como sostenían los griegos, y también de acción como sostenían los romanos. La filosofía deja de tener su centro en el ser humano; ahora se encuentra fuera del hombre, en Dios; y es conocimiento de Dios y a través Suyo es conocimiento de todo, dirigido por Él, sometido a la revelación y a ciertas verdades que él mismo nos descubre por su Voluntad. En síntesis, el amor a la sabiduría, propio de la filosofía, aquí será el amor a Dios.

\section{La filosofía como amor a sí mismo (Renacimiento)}

Las filosofías anteriores al Renacimiento no pretendían fundar la filosofía en el Yo humano. El centro del pensamiento lo ocupaban las cosas con sus ideas como hacían los griegos, las cosas y las acciones como realizaban los romanos, o bien Dios como los filósofos cristianos. Para estas filosofías, el hombre era una cosa más o menos privilegiada, pero nunca tanto que pudiera llegar a ser el fundamento de la Filosofía. Con René Descartes (siglo XVI y XVII) la filosofía se asienta en el Yo, en el cógito, ergo sum (pienso, luego, existo), obtenido a través de su duda metódica. Todo lo puedo poner en duda, menos que dudo, y si dudo soy una cosa que piensa. La duda me confirma que pienso y si pienso soy algo. Si uno piensa que existe, es verdad y es real que existe; pero si uno piensa que no existe, existe a pesar de pensar tal falsedad. El hombre es un ser que tiene ideas sobre las cosas, sobre Dios, sobre el mismo hombre. Analizando esas ideas podemos llegar a las ideas claras y distintas. Lo cual nos indica que la realidad de las ideas es superior a la realidad que puede ser aparente. Descartes estudiará qué ideas se me presentan indubitablemente, sin ninguna duda, como el cógito, y sostendrá que toda idea clara y distinta es verdadera. Así llegará entre otras conclusiones a mostrar la existencia de Dios, la inmortalidad del alma, partiendo de las ideas que se hallan 
en nosotros, que somos un nuevo punto de partida de la Filosofía y de la verdad. Es un nuevo idealismo filosófico. En resumen, en Descartes, el amor a la sabiduría toma la forma del amor al Yo, un amor a sí mismo, y por él llegará a las demás cosas.

\section{La filosofía como amor a sí mismo en cuanto ordenador del mundo}

En el siglo XVIII nos encontramos con Inmanuel Kant con una dirección también idealista. La Filosofía tiene como tarea propia ordenar las cosas del mundo mediante el YO. En rigor, no podemos sostener si las cosas existen fuera del yo, ni qué son en sí mismas. Es el Yo el que ordena los datos del mundo real, las hace inteligibles a través de las formas a priori de la sensiblidad, como son el concepto de espacio y de tiempo. Según Kant, la razón pura transforma la materia y los datos sensibles, tal vez caóticos del mundo real, de manera que nos resulten inteligibles. Esta manera de concebir el mundo se llama Idealismo trascendental. No sabemos lo que son las cosas en sí mismas, pero sí sabemos que son para el hombre, que las ordena mediante la razón. Es el Yo el que transforma las cosas y hace con ellas cosas inteligibles. Esta dirección de la filosofía se llama idealista porque se parte del yo y de las ideas que tiene el yo. Por el contrario, la otra dirección de la filosofía es el realismo, que es la tendencia a no transformar las cosas, a contemplarlas tal como son, sin referirlas al hombre o al sujeto o al yo o a la razón; es por tanto, contemplar la realidad de las cosas, las cosas en sí, no las ideas de ellas, no lo que son para mí, como hacen los idealistas.

\section{La filosofía como amor a sí mismo y a las cosas}

La filosofía contemporánea ha querido hacer un puente entre el idealismo y el realismo. La realidad no puede ser sólo una construcción del sujeto, ni una descripción objetiva de las cosas. Sujeto y objeto son importantes en la labor del conocimiento de la realidad. La pregunta es: ¿qué límite imponen las cosas a las tendencias constructivistas 
de la razón? Es decir, la realidad que edifica la razón (idealismo) ¿no tendrá que contar con ciertas propiedades suyas que la razón tendrá que aceptar, sin poder elaborar más, así como un constructor o un albañil tiene que contar con la resistencia típica de la materia como la madera, el fierro, el ladrillo? En otras palabras, las cosas están más allá del sujeto, son independientes de la mente o sujeto que las capta. Esta tendencia a reconocerle a las cosas propiedades suyas, independientes del sujeto, sobre las cuales no tenemos, ni tiene la razón, poder alguno, tiene un famoso lema: ¡A las cosas mismas! Volvamos a las cosas, conozcamos lo que son en sí mismas. Es la corriente fenomenológica instaurada por Edmund Husserl, seguida por muchos pensadores. Podemos intuir, contemplar algunos objetos, buscarles su esencia, pero no podemos transformarlos. Es el caso de los números y las figuras. Por ejemplo el 1, o el círculo, no es mi acto de pensarlo, no se halla colocado en el tiempo, no tiene lugar específico como lo tiene Platón o cualquier filósofo grande o pequeño que haya existido. De modo que Husserl, en cierta forma vuelve al filosofar griego, en cuanto la filosofía es contemplación de ideas, de esencias descubriendo las realidades interiores que permanecen firmes. La filosofía, en este caso, es el amor a las cosas mismas, porque ellas se manifiesten a sí mismas por sí mismas; o sea, nada de construcciones ni intervenciones artificiales del sujeto que capta los fenómenos.

Otro gran filósofo del siglo XX, con múltiples discípulos, es Wilhelm Dilthey, que propone estudiar la vida en sus manifestaciones históricas, especialmente: la vida del lenguaje, la vida social, la vida de la poesía, la vida de la Historia misma, la vida de la Metafísica, etc.; pero también con el plan consciente de no construir nada como el idealismo, de no meter mano en las cosas de la vida, sino dejar que ellas y sólo ellas nos hablen lo más directamente posible. Ahora la palabra clave no es construir, sino interpretar. La filosofía es interpretación, hermenéutica. Luego, Dilthey introducirá el método hermenéutico, que significa en griego lo que en castellano interpretación. Y así como una persona interpreta las señales que le hace un amigo para que se aparte del peligro, pero las señales no hacen nada real, así el método 
hermenéutico intenta encontrar el sentido de las cosas de la vida, por ejemplo: qué nos quiere decir el arte con sus expresiones, qué ha querido decirnos la vida con la religión, con la música, sin proponerse transformar ni construir tales datos. O sea a las cosas mismas, a las cosas de la vida.

\section{La filosofía como amor a conocerse (autognosis)}

Una de las preguntas más radicales que puede hacerse un pensador es qué es el hombre (y en particular quién soy yo). La autognosis es para algunos pensadores la reflexión filosófica por excelencia. En rigor, es un tema predilecto de la filosofía: la antropología filosófica. Kant señaló que cuatro eran las preguntas principales de los filósofos: ¿qué puedo saber?, ¿qué debo hacer?, ¿qué me está permitido esperar?, y la última que las contiene a las tres restantes: ¿qué es el hombre? Si nos retrotraemos al tiempo de los griegos, nos encontramos que en el famoso templo dedicado a Apolo en Delfos, había la siguiente inscripción: conócete a ti mismo", consejo que practicó Sócrates con sus conciudadanos. Un filósofo del siglo XX: Ernst Cassirer, afirma también que la autognosis constituye el propósito supremo de la indagación filosófica. Han sido múltiples las respuestas que se han dado a través de la historia sobre qué es el hombre. A continuación presentamos una lista de ellas:

\section{Respuesta}

Fuente

\begin{tabular}{|l|r|}
\hline Bípedo implume & Burlesca fórmula de Platón \\
\hline $\begin{array}{l}\text { Animal dotado de logos, por tanto de } \\
\text { habla y razón }\end{array}$ & Aristóteles \\
\hline Animal Rationale & $\begin{array}{r}\text { Versión medieval de la } \\
\text { definición aristotélica }\end{array}$ \\
\hline $\begin{array}{l}\text { Ente cuya realidad es a la vez opus Dei, } \\
\text { Obra de Dios, opus alterum per alterum, } \\
\text { Alguien que se realiza con los otros y } \\
\text { por los otros, y opus cum creatura, cuerpo } \\
\text { viviente en conexión dinámica con todo } \\
\text { el cosmos }\end{array}$ & Hildegarda de Bingen \\
\hline
\end{tabular}




\begin{tabular}{|l|r|}
\hline $\begin{array}{l}\text { Suma unitaria de una cosa extensa y una } \\
\text { cosa pensante }\end{array}$ & Descartes \\
\hline Pequeño Dios & Kant \\
\hline $\begin{array}{l}\text { Organismo regido por un principio vital y } \\
\text { un alma espiritual }\end{array}$ & Vitalismo del siglo XVIII \\
\hline $\begin{array}{l}\text { Ente a un tiempo físico, en cuanto } \\
\text { Fenómeno, y moral, en cuanto nóumeno }\end{array}$ & Hegel \\
\hline $\begin{array}{l}\text { Parte individual-personal de la } \\
\text { humanidad, entendida ésta como } \\
\text { deviniente. }\end{array}$ & Materialismo siglos XVIII \\
\hline Máquina especialmente complicada \\
\hline Homo sapiens y homo faber & Zoólogos y antropólogos \\
de los siglos XVIII y XIX \\
\hline $\begin{array}{l}\text { Animal que puede prometer y capaz de } \\
\text { superarse a sí mismo }\end{array}$ & Nietzsche \\
\hline $\begin{array}{l}\text { Animal que puede decir no a la } \\
\text { satisfacción del instinto, asceta de la vida }\end{array}$ & Scheler \\
\hline $\begin{array}{l}\text { Animal capaz de expresión y } \\
\text { comunicación simbólica }\end{array}$ & Cassirer \\
\hline Animal al que hace enfermo el espíritu & Klages \\
\hline $\begin{array}{l}\text { Animal hacedor de su ser y capaz de } \\
\text { ensimismamiento }\end{array}$ & Heidegger \\
\hline Pastor del ser & Ortega y Gasset \\
\hline Pasión inútil \\
\hline $\begin{array}{l}\text { Sustantividad de propiedad, esencia } \\
\text { abierta y animal de realidades }\end{array}$
\end{tabular}

También se ha sostenido que el hombre es el animal creador de cultura o el animal estético, creador de belleza, o el animal religioso, que aspira a la trascendencia, etc. Como podemos ver son múltiples las definiciones de lo que es el hombre. Ahora bien, todas estas son acercamientos desde la filosofía. Otras ciencias o disciplinas como la psicología, la educación y otras también pueden colaborar en esta tarea. Lo que sí está claro -pensamos- es que el hombre se muestra a través de sus obras como el lenguaje, el arte, la religión, la ciencia, la filosofía, etc. "En todas ellas -escribe Cassirer- el hombre descubre y prueba un nuevo poder, el de edificar un mundo suyo propio, un mundo ideal. La filosofía no puede renunciar a la búsqueda de una unidad fundamental en este mundo ideal. Pero no tiene que confundir esta unidad con la 
simplicidad. No debe ignorar las tensiones y las fricciones, los fuertes contrastes y los profundos conflictos entre los diversos poderes del hombre... Tienden en direcciones diferentes y obedecen a diferentes principios, pero esta multiplicidad y disparidad no significa discordia o falta de armonía. Todas estas funciones se completan y complementan, pero cada una de ellas abre un nuevo horizonte y muestra un nuevo aspecto de lo humano" (Cassirer, Pág. 334).

Pero ¿quién es el hombre, filosóficamente hablando, para nosotros? Los resultados de varias doctrinas de la filosofía contemporánea nos ayudarán a responder esta pregunta ${ }^{7}$. Lo propio del hombre es "ser consciente de sí en el propio acto de ser consciente de los demás". ${ }^{8}$ Su ser radica en la capacidad de verse a sí mismo. Se le llama entonces 'ser para sí', contrastándolo con el 'ser en sí' de todo lo demás. "No se trata, pues -escribe Jorge Millas-, sólo de que el hombre tenga conciencia, también la tiene el animal, en cuanto ve y siente las cosas del mundo en torno y reacciona frente a ellas (atacándolas y huyendo). Lo propiamente humano es que, consciente de las cosas, el hombre es a la par consciente de sí como sujeto activo y pasivo de sus relaciones con ellas ${ }^{\prime \prime}$. De aquí se desprenden cuatro características fundamentales del hombre:

a) El ser del hombre es un proyecto, una empresa que se va realizando, un proceso que se va configurando, desarrollándose, en contraste con las cosas en que su ser está irremediablemente hecho, dado, de una vez por todas.

b) En este ir haciéndose, desplegándose, el hombre va decidiendo, optando. Es decir, puede elegir. Está condenado -como afirma Jean Paul Sartre- a ser libre. Eso sí, su libertad está condicionada y determinada por el tiempo, la época y las relaciones circunstanciales. Las cosas no tienen ninguna opción de ser otra cosa

Véase MILLAS, Jorge. Idea de la Filosofía. Editorial Universitaria, Santiago, 1970. Págs. 40 a 42.

8 Ibídem, Pág. 41.

9 Ibídem, Pág. 41. 
que ellas mismas. Su ser es fijo. En cambio, el hombre al no tener hecha su vida, va resolviendo su ser dentro de un marco que está dado de antemano: el mundo. Su libertad es, por tanto relativa. El filósofo Ortega y Gasset lo expone de la siguiente manera: "el mundo vital se compone en cada instante para mí de un poder hacer esto o lo otro, no de un tener que hacer por fuerza esto y sólo esto. Por otra parte, esas posibilidades no son ilimitadas; en tal caso no serían posibilidades concretas, si no la pura indeterminación, en que todo es posible, y en un mundo de absoluta indeterminación, en que todo es posible, no cabe decidirse por nada. Para que haya decisión tiene que haber a la vez limitación y holgura, determinación relativa... Vida es, a la vez, fatalidad y libertad ${ }^{\prime 10}$, es ser libre dentro de una fatalidad dada.

c) El hombre, además de ser consciente de sí, es conciencia de los demás, de todo aquello que no es él, de lo que es objeto para su conciencia, de su mundo, de su realidad circundante. Toda conciencia -como sostiene Edmund Husserl- es conciencia de algo. Tiene 'intencionalidad' o trascendencia de ella misma. Apertura al mundo ya sea cosas materiales, espirituales o ideales.

d) La conciencia humana, junto a lo anterior, es también conciencia del deber ser y no sólo del ser. Su conducta está referida a valores: al bien y al mal; a lo mejor y a lo peor; a lo positivo y negativo. Este hecho lo distancia aún más de los objetos y de los animales. El hombre vive de acuerdo a una escala de valores. El ser humano, quiéralo o no, tiene conciencia y una libertad relativa.

Resumiendo lo anterior podemos reconocer que a través de la historia de la filosofía se han presentado diversas formas de llevarla a cabo,

10 ORTEGA Y GASSET, José. ¿Qué es Filosofía? Revista de Occidente. Alianza Editorial, Madrid, 1985, Pág. 205. 
reflexionando sobre el yo pensante y sobre el mundo; es decir, la filosofía se ha concebido como una concepción del yo o una concepción del mundo o una mezcla de ambos... pero ¿habrá otra forma de concebirla?, ¿una forma antigua y nueva a la vez? Pensamos que sí; es la filosofía práctica.

\section{Hacia una filosofía práctica de vida}

En honor a la verdad cualquier suceso o situación, especialmente aquellas llamadas "situaciones límites" como la muerte, el amor, el sufrimiento, pueden ser un acicate para dedicarse a la actividad filosófica. Esto no significa -como algunos piensan- que todo ser humano es filósofo o que deseamos que todo el mundo sea filósofo. Lo que sí sostenemos es que todo ser humano se ha hecho preguntas filosóficas y ha tratado de responderlas, pero esta situación no lo convierte en filósofo. Por tanto, reconocemos preguntas filosóficas, actividades filosóficas y filósofos. Los filósofos son personas que se dedican constantemente a la filosofía, y ésta es una disciplina seria, sistemática y absorbente, un proyecto de vida al que no es fácil dedicarse en el mundo contemporáneo. Si alguna vez uno realiza una curación eso no lo hace ser médico, si alguien escribe un artículo, eso no lo convierte en escritor. Si uno se plantea una pregunta filosófica eso no lo hace ser filósofo. La filosofía, como nosotros la entendemos, más que una profesión es un estilo de vida, en la cual el pensamiento sistemático y riguroso se convierte en un fin, y además, donde el conocimiento de sí mismo es su objetivo principal. No obstante lo anterior, lo que sí esta claro es que cualquier persona puede tener una filosofía de vida, que le ayude a enfrentar su propia existencia, la cual consiste en una visión panorámica sobre el hombre, el mundo y Dios, que son los ejes principales para ordenar el pensamiento. En ese sentido hay un excelente estímulo para filosofar, ya que todo ser humano, consciente o no, tiene una filosofía de vida. Luego, quisiéramos motivar a los lectores para que sean conscientes de su filosofía de vida, la cual llamaremos "filosofía práctica o también filosofía doméstica". Al respecto, podemos distinguir en líneas muy gruesas dos grandes tipos de 
filosofía: una teórica y una práctica. La primera es la especialidad de los pensadores académicos, aquellos que conocen, estudian, analizan los grandes filósofos de todos los tiempos, escriben libros y artículos sobre ellos, con términos bastante alejados del hombre común; así son expertos en un filósofo o varios de ellos, o en un tema propio de la filosofía, por ejemplo: la belleza, el bien, el mal, la democracia, etc. Suele llamarse filosofía analítica. "Esta clase de filosofía es, en su mayor parte, abstracta y autorreferencial, y dice muy poco o nada acerca del mundo. Rara vez puede aplicarse a la vida. Dicho enfoque es apropiado para las universidades." 11 Son los "especialistas de la filosofía", que viven en una especie de torre de marfil o en catacumbas académicas, distantes de la vida cotidiana y con un lenguaje difícil de entender para la persona común. (Esta situación no solamente les ocurre a los filósofos sino a cualquier científico).

La filosofía teórica o especulativa surgió sobre todo de la reflexión y estudio riguroso de los filósofos y sus obras, de la admiración o de la crítica a sus pensamientos. La filosofía práctica o sapiencial, en cambio, se originó esencialmente del cómo vivir. De allí la importancia del lema "conócete a ti mismo", que es el inicio de la filosofía práctica, y que alude al reconocimiento del hombre como un ser distinto de Dios, con sus habilidades y también limitaciones, con sus fortalezas como con sus debilidades. Entonces, aquí la búsqueda filosófica surge de la pregunta ¿quién soy?, para derivar a la pregunta ¿qué es el hombre?, y llegar a la pregunta de las preguntas: ¿qué o quién es Dios? Si la filosofía teórica surge de la lectura seria y sistemática de los textos de los filósofos, la filosofía práctica brota del conocimiento de sí mismo. Llegar a conocerse es mucho más que mirarse pasivamente al espejo del interior; es iniciar un proceso de búsqueda, de descubrimiento y transformación personal.

11 MARINOFF, Lou. Más Platón y menos Prozac. 2000. Ediciones B, Barcelona, Pág. 22. Véase también CAVALLÉ, Mónica. La Sabiduría recobrada, 2006, Ediciones Martínez Roca, Madrid, Págs. 15-16. Mónica Cavallé es en la actualidad presidenta de la Asociación Española para la Práctica y el Asesoramiento Filosóficos (ASEPRAF). 
La filosofía práctica es aquella que ha proporcionado pensamientos a las personas que pueden ser utilizados para la vida de todos los días. Esta forma de entender la filosofía está más cercana de lo que hacían los filósofos epicúreos, los estoicos, etc., es decir, la filosofía como el arte de vivir bien. "Tanto Sócrates, que se pasaba el día debatiendo cuestiones de gran importancia en el ágora, como Laozi, que recopiló sus consejos sobre cómo seguir el camino del éxito evitando todo perjuicio, querían que sus ideas fuesen de utilidad. La filosofía al principio, era una forma de vida, no una disciplina académica; es decir, no sólo objeto de estudio sino también de aplicación" ${ }^{\prime 12}$ La filosofía académica o analítica se ha extendido demasiado en detrimento de la filosofía práctica. Por tanto, quisiéramos estimular a los lectores a volver a la filosofía práctica, aquella que está relacionada con la vida real y concreta, apoyados con los pensamientos de los grandes filósofos, pero pasadas por el tamiz de la reflexión personal. En efecto, "todo el mundo tiene una filosofía de vida pero pocos de nosotros gozamos del privilegio o el tiempo libre necesario para sentarnos a esclarecer sutilezas. Tendemos a irlo haciendo sobre la marcha. La experiencia es una gran maestra, pero también precisamos reflexionar sobre nuestras experiencias. Necesitamos pensar con una postura crítica, buscando pautas de conducta y situándolo todo en el contexto general para abrirnos camino en la vida. Comprender nuestra propia filosofía puede ayudarnos a evitar, resolver o abordar muchos problemas". ${ }^{13}$ Sin embargo, también nuestra filosofía puede ser el origen de los problemas que sufrimos, de manera que sería necesario evaluar nuestras ideas para forjar pensamientos que obren a favor y no en contra de nosotros. Las preguntas fundamentales de la filosofía son cuestiones que todos nos hemos preguntado: ¿de dónde proceden todas las cosas?, ¿existe Dios?, ¿qué es una vida buena?, ¿qué es el bien y el mal?, ¿cómo debo obrar correctamente?, ¿cuál es el sentido de la vida y de la muerte?, ¿tenemos libre albedrío? En rigor, son preguntas que pueden tener múltiples respuestas, y mu-

12 Ibídem, Pág. 21.

13 Ibídem, Pág. 18. 
chas veces no encontramos las respuestas requeridas. Es aquí donde podemos beneficiarnos de la filosofía práctica, del inmenso cúmulo de sabiduría que nos han legado los filósofos y directrices acerca de cómo vivir.

Lo que pretendemos en este escrito es que dejemos de lado la filosofía puramente teórica o especulativa y podamos aplicarla a los problemas cotidianos de la vida personal, social y profesional, llevar la filosofía de la academia a la vida concreta. John Dewey sostenía que la filosofía se recobra a sí misma cuando deja de ser un invento de los filósofos y se convierte en un método cultivado por ellos para solucionar los problemas de los hombres ${ }^{14}$. William James, el padre del pragmatismo, escribió: "Sé que cada uno de vosotros, señoras y caballeros, tenéis una filosofía, y que lo más importante e interesante con respecto a vosotros es la manera con que ello determina la perspectiva en vuestros mundos respectivos. Sabéis lo mismo de mí. Es más: confieso cierta timidez ante la audacia de la tarea que he de emprender. Para la filosofía, tan importante en cada uno de nosotros, no es cuestión de técnica; es nuestro más o menos oculto sentido del significado de una vida honesta y profunda". ${ }^{15}$ La filosofía, en ese sentido, es entendida como nuestra manera personal de ver y sentir el mundo, es nuestra visión de mundo, nuestra concepción del universo; si somos creyentes o no, si los valores que nos orientan son la vida, la libertad, la justicia, u otros, si creemos en el ser humano o más bien en los animales, si no tenemos confianza en nada ni nadie o sólo en nosotros mismos, si somos optimistas o pesimistas, si pensamos que cada ser humano es el arquitecto de su destino o éste ya está prefigurado, etc. William James nos entrega la siguiente recomendación: "lo que necesitáis es una filosofía que no solamente ponga a prueba vuestra capacidad de abstracción, sino que produzca también alguna

14 Nina Bravo Donoso, una profesora de filosofía chilena escribió un libro muy pedagógico en torno a este tema que ya lleva muchas ediciones: Valores Humanos. Por la senda de una ética cotidiana. RIL Editores, Santiago, 2001. 15 JAMES, William. El Pragmatismo. Editorial Américalee, Buenos Aires, 1945, Pág. 25. 
conexión positiva con ese mundo real de vidas humanas y finitas" ${ }^{16}$ La filosofía práctica quiere recuperar las grandezas de la vida cotidiana y también sus detalles.

Alcanzar una filosofía práctica requiere del esfuerzo y reflexión personal, pero también puede recurrir si lo desea a la sabiduría que se ha ido forjando a través de los milenios y de los siglos, de las ideas que nos han dejado los grandes filósofos, aquellos pensamientos atemporales sobre la existencia y la condición humana. Estos pensamientos pueden orientar a las personas tratando sus problemas con filosofía en una especie de terapia filosófica, y también ayudarles a obtener su filosofía de vida; sin embargo -como afirmamos más arriba- eso no los convierte en filósofos. Lou Marinoff, profundo conocedor de la filosofía práctica y del asesoramiento filosófico señala: "De ningún modo es necesario ser doctor o licenciado en filosofía para beneficiarse de la sabiduría de todos los tiempos. Al fin y al cabo, tampoco necesita estudiar biofísica para dar un paseo, ser ingeniero para plantar una tienda de campaña o ser experto en economía para encontrar empleo. De la misma forma, no necesita estudiar filosofía para llevar una vida mejor, aunque tal vez necesite practicarla. ${ }^{17}$ La filosofía, entonces, se convierte en una guía práctica para los dilemas más frecuentes de la vida, es una filosofía cercana a la gente y que la orienta. Esto no significa que desechemos la filosofía más académica o teórica, sino que ésta debe seguir haciéndose en las universidades o institutos, tal cual se hace una investigación o ciencia pura, pero también como en el caso de las ciencias hay que contar con una rama aplicada, que en el caso de la filosofía es la filosofía práctica. Esta vertiente proviene desde la antigua Grecia con Sócrates y los estoicos. A principios del siglo XX fue defendida por John Dewey, entre otros. Este último escribió: "Uno de los sentidos populares de la filosofía es la serenidad y la resistencia frente a las dificultades y pérdidas, y hasta se supone que es un poder para sufrir el dolor sin

$16 \quad$ Ibídem, p. 35.

17 MARINOFF, Lou. Más Platón y menos Prozac. Op. Cit. Pág. 23. 
quejarse. Este significado es un tributo a la influencia de la filosofía estoica más que un atributo de la filosofía en general. Pero se justifica en todo esquema en cuanto sugiere que la característica total de la filosofía es el poder de aprender, o de extraer, el significado hasta de las vicisitudes desagradables de la experiencia, y de encarnar lo que se ha aprendido en la capacidad para seguir aprendiendo." ${ }^{18}$ Luego, queremos devolver a la filosofía práctica el lugar que le corresponde y a los filósofos prácticos su gran valor y dignidad, en el tiempo actual, son los asesores filosóficos: "En el mundo antiguo, así como a lo largo de la historia, los filósofos estaban a disposición de quien precisara orientación para superar los malestares de la vida; sin embargo, en el mundo moderno se han ido haciendo cada vez menos asequibles, y más inaccesibles e irrelevantes ante tales preocupaciones. Con todo, la gente ha echado de menos la clase de consejo que los filósofos pueden dar, así como la variedad de puntos de vista que son capaces de proponer". ${ }^{19}$ Así la filosofía deja de ser una prestidigitación teórica para ser un arte de la vida tal como lo era en la época de las grandes escuelas filosóficas de la antigüedad como el estoicismo, epicureismo, escepticismo, aquella época denominada el Helenismo que fue un largo período desde el siglo IV a. C hasta el siglo IV d. C. En efecto, en el helenismo "la filosofía toma un sesgo diferente. Ya no se intenta saber por amor a la sabiduría, sino como medio para vivir y ser felices, y la filosofía se reduce, en consecuencia, a ética. La filosofía en este período, precisamente por su función eminentemente práctica, gana en extensión, pues será el instrumento al que en sustitución de los valores tradicionales deberán acudir los hombres de la época para resolver sus problemas existenciales." ${ }^{20}$ Sin embargo, queremos reiterar que la filosofía práctica no debe ser un asunto del pasado, de un glorioso pasado que nos sumerge en la

18 DEWEY, John. Democracia y Educación, Editorial Losada. Buenos Aires, 1953, Pág. 335

19 MARINOFF, Lou. Pregúntale a Platón. Cómo la filosofía puede cambiar tu vida. Ediciones B, Barcelona 2003, Pág. 23.

20 YARZA, Iñaki. Historia de la Filosofía Antigua. Ediciones Universidad de Navarra, Pamplona, España, 1992, Págs. 192-193. 
melancolía de otras épocas. Su utilidad es evidente ahora como antes. Actualmente la gente común pide a los filósofos una orientación para los problemas existenciales, una síntesis superior, una sabiduría de vida. Se requiere -entonces- de filósofos muy preparados en el arte de saber vivir y también en toda la tradición filosófica, para poder aplicarla a los problemas reales de las personas. Mónica Cavallé, filósofa práctica contemporánea, sostiene que hay dos tipos de filosofía: la especulativa y la sapiencial. La primera se enseña en las aulas y predomina en los ámbitos académicos y especializados. La segunda "es ante todo, una sabiduría de vida: un conocimiento indisociable de la experiencia cotidiana y que la transforma de raíz, un camino de liberación interior. Más que una doctrina o una serie de doctrinas teóricas autosuficientes, es un conjunto de indicaciones operativas, de instrucciones prácticas para adentrarnos en dicho camino. La filosofía así entendida se propone inspirar más que explicar; no nos invita a poseer conocimientos, sino a acceder a la experiencia de un nuevo estado de saber y de ser, cuyos frutos son la paz y la libertad interior" (Cavallé, Mónica, pp. 15-16). Aquí la filosofía es concebida como una terapia para las personas comunes en la vida cotidiana. Su función no es sólo el conocimiento sino una transformación a partir de los pensamientos.

\section{El asesoramiento filosófico: filosofía práctica para el siglo XXI}

A fines del siglo XX surge con mucha fuerza una tendencia muy práctica en el campo de la filosofía, denominada 'asesoramiento filosófico' y que hoy tiene una gran lista de organizaciones de filosofía práctica en todas partes del mundo: Estados Unidos, Canadá, Alemania, Israel, Países Bajos, Reino Unido, etc. ${ }^{21}$ Consiste en el apoyo y consejo de gente preparada en filosofía, a personas, grupos y empresas, para afrontar

21 Para un listado de Organizaciones de filosofía práctica véase MARINOFF, Lou. Más Platón menos Prozac, Op. Cit. Págs. 371-374. También puede buscarse en Internet como filosofía práctica y asesoramiento filosófico. 
las dificultades propias de la vida, recurriendo a los pensamientos e ideas de las mentes más sabias de la historia. Es -por tanto- una ayuda a las personas, a partir de los pensamientos de grandes filósofos y corrientes filosóficas para enseñar a abordar los principales aspectos de la vida cotidiana. Lou Marinoff escribe: "Aunque muchos de nosotros estemos doctorados en filosofía, enseñemos en universidades y publiquemos artículos especializados, hacemos algo más que eso: también ofrecemos asesoramiento a clientes individuales, a grupos y a organizaciones. Apartamos la filosofía de los contextos puramente teóricos o hipotéticos y la aplicamos a los problemas cotidianos de la vida personal, social y profesional." ${ }^{22}$ El asesoramiento filosófico se inspira en los más grandes filósofos y filosofías de la historia del mundo para enseñarle a las personas o instituciones a solucionar los problemas de modo filosófico. Se trata de beneficiarse de la sabiduría de todos los tiempos para superar los problemas cotidianos que los seres humanos tenemos: cómo conducir las relaciones amorosas, cómo plantearse el tema de la muerte, cómo enfrentar los cambios que nos depara la vida, cómo encontrar sentido a la existencia, etc. En otro de sus libros, Marinoff sostiene: "Por filosofía no me refiero sólo al estudio de ideas abstractas por su valor intrínseco. Eso está muy bien para los eruditos, que disfrutan en el debate de la teoría por la teoría, pero la filosofía también puede ayudar a la gente corriente, mediante la aplicación de ideas útiles a sus problemas concretos de la vida cotidiana. ${ }^{23}$ Así la filosofía vuelve a ser la maestra de la vida, una guía práctica para vivir mejor. Una persona común, generalmente no le va a preguntar a un filósofo: ¿qué quiso decir Heidegger con la frase "el lenguaje es la casa del ser" o que significa la frase de Hegel "todo lo racional es real y todo lo real es racional"? Esas preguntas le interesan a la gente especializada en filosofía, no a la gente corriente, en el mejor sentido de la palabra. Pero sí a estas personas les va a interesar cómo vivir más tranquilamente, qué puedo hacer para ser feliz, cómo decidir mejor en la vida, etc. Es allí donde la filosofía puede tener una palabra frente a

23 MARINOFF, Lou. Pregúntale a Platón, Op. Cit. Pág. 15. 
los problemas que se ciernen de vez en cuando o muchas veces, en la vida de cada ser humano o de una institución. De modo más general, la filosofía también tendrá que decir alguna palabra ante las amenazas del oscurecimiento del mundo, del predominio de la tiranía, de la injusticia, del absurdo, de la sinrazón, del mal desatado. Queremos rescatar a la filosofía del academicismo en el que ha caído por parte de muchos de sus cultores y de aquellos que decretan su anacronismo o, incluso, su muerte. El asesoramiento filosófico es un arte más que una ciencia y también se le denomina terapia filosófica. Tiene personas especialistas, los llamados asesores o consejeros filosóficos. Son ellos los llamados a orientar a las personas o grupos humanos pues manejan las ideas de los filósofos y de los sistemas filosóficos más importantes de la historia, la sabiduría acumulada a través de los siglos. Luego, ellos requieren una sabiduría y una prudencia que no es fácil adquirir. Si bien es cierto, hay tantas variantes como consejeros que lo practiquen, el asesoramiento filosófico propone algunos recursos para solucionar problemas con filosofía. Entre otros, queremos destacar, el proceso PEACE y MEDIO.

PEACE es un acrónimo de las iniciales de las cinco etapas que componen el proceso; Problema, Emoción, Análisis, Contemplación y Equilibrio. Si seguimos estos pasos -según Marinoff- la persona puede enfrentar los asuntos desde una óptica filosófica. Lo primero es identificar el problema, clarificarlo: por ejemplo, un familiar se está muriendo, o lo han despedido del trabajo, un asunto de infidelidad, no le gusta su carrera, etc. El segundo paso consiste en hacerse una introspección con una lista de las emociones que le provoca el problema. ¿Cuáles son estas emociones?, ¿rabia, tristeza, miedo, angustia, o una mezcla de varias? El tercer lugar es el análisis. Aquí se enumeran y examinan las distintas opciones de que se dispone para la solución del problema. En rigor, se trata de analizar los distintos caminos que tiene que recorrer mentalmente para encontrar la opción más adecuada. En el cuarto paso, se trata de tomar distancia del problema, así como la montaña es más clara desde el llano para el montañés, es la etapa de contemplación. Consiste en contemplar su situación en conjunto, 
cultivando una visión filosófica unificada. En esta etapa, ya se tiene claro el problema y las emociones que le provoca; además se han evaluado las opciones a través de un análisis serio y sistemático. "En este punto ya está preparado para considerar métodos, sistemas y enfoques filosóficos para abordar la situación que le afecta en su globalidad... Tiene que adoptar, mediante la contemplación, una postura filosófica que al mismo tiempo se justifique por méritos propios y esté en consonancia con la naturaleza de su persona". ${ }^{24}$ Aquí se puede encontrar un pensamiento que esté de acuerdo con sus propias ideas. Después de contemplar la situación desde una óptica filosófica, viene la etapa final: alcanzar el equilibrio. Se trata de entender la esencia del problema y estar preparado para emprender actos adecuados y justificables, actuar de acuerdo a todo lo aprendido con mesura y prudencia. En definitiva, es encontrar paz interior, serenidad ante las cosas y apertura al misterio. Explicar las etapas es en general sencillo, pero llevarlas a la práctica puede requerir en el mejor de los casos de una sesión o de muchas sesiones.

Otro método del asesoramiento filosófico es el proceso MEDIO. Si el método PEACE, nos puede orientar a enfrentar los problemas cotidianos de modo filosófico, este método nos ayuda a reconocer la filosofía de vida personal. Según Marinoff, este proceso le ayudará a examinar filosóficamente su vida, en rigor le va a permitir diseñar su filosofía de vida. MEDIO es el acrónimo de los Momentos decisivos, las Expectativas, el Doble vínculo, los Impulsos negativos y las Opciones sagaces. Ahora bien, aquí no se trata de un proyecto de un día, la verdad es que requiere de mucho tiempo y esfuerzo reflexivo, es la construcción de su casa filosófica.

Los Momentos decisivos son aquellos hechos en los cuales las circunstancias nos ponen seriamente a prueba: un accidente, una enfermedad, una ruptura, un despido del trabajo, etc. Circunstancias que "nos arrebatan el bienestar habitual de nuestra vida y dejan al des-

24 MARINOFF, Lou. Más Platón y menos Prozac, Op. Cit. Pág. 62. 
cubierto lo bien o mal preparados que estamos para desenvolvernos. La preparación no es otra cosa que nuestra filosofía de vida. ${ }^{25}$ En general, las personas casi nunca cuestionan los buenos momentos; por el contrario, en los malos momentos, casi todo el mundo se hace preguntas filosóficas: ¿por qué esto me ocurre a mí?, ¿qué significado tiene lo que está pasando?, ¿qué debería hacer con mi vida?, ¿dónde está Dios?, ¿existe Dios?, ¿qué es el amor?, ¿es justo el mundo?, ¿por qué hay dolor?, etcétera.

Las Expectativas son el siguiente paso en la construcción de la filosofía personal. Todos nosotros tenemos expectativas, esperanzas y deseos. Cuanto más esperemos de la vida, ésta nos puede causar daño, luego, las expectativas no realizadas nos pueden provocar mucha frustración. Marinoff escribe: "Cada una de sus expectativas lo proyectan hacia un episodio de malestar. Despréndase de ellas y se desprenderá también del malestar." 26 Sabemos que no es fácil desprenderse de las expectativas, sin embargo, sería prudente no esperar demasiado de las personas, ni de las circunstancias.

Más adelante, está el tema del Doble Vínculo. En efecto, todas las personas desarrollamos vínculos, tanto beneficiosos como perjudiciales. Así podemos tener vínculos profundos con personas o con hechos; piénsese en una amistad o en un hobby. Aquí nos podemos encontrar con dos tipos diferentes: las aficiones y las aversiones; por ejemplo: afición a una música o un deporte, por un lado; aversión a las arañas o a una comida, por otro lado. Si una afición es muy fuerte puede transformarse en una obsesión, y una aversión transformarse en un prejuicio. Los vínculos muy establecidos pueden ser causa de malestar y desdicha, por tanto, disminuyéndolos podemos encontrar posibilidades de disfrutar de bienestar. Así la afición por una persona puede derivar en sentimiento de posesión. Necesitamos de los vínculos pero es importante no llevarlos demasiado lejos, saber desapegarse de ellos. "la mejor opción es tener sólo vínculos positivos y evitar tener

25 MARINOFF, Lou. Pregúntale a Platón, Op. Cit. Pág. 331.

26 MARINOFF, Lou. Pregúntale a Platón, Op. Cit. Pág. 334. 
vínculos negativos" ${ }^{27}$ Los vínculos positivos nos hacen crecer como personas; en cambio, los negativos producen frustración.

Los Impulsos negativos son el siguiente paso en la construcción de la casa filosófica. Los impulsos son aquellas emociones, sentimientos, tendencias que tarde o temprano se nos hacen presentes en la vida. Algunos de ellos como el enfado, la rabia, el odio, nos impulsan a hacer el mal en lugar de el bien, también a experimentar y causar malestar a otras personas. Es legítimo sentir, pero ¿se puede canalizar esa energía negativa? Según Marinoff, podemos transformar esos impulsos, neutralizándolos o convirtiéndolos en energía positiva. "Por 'energía neutra' me refiero a una actividad o distracción que nos permita disipar el enfado sin dañar a nadie. El ejercicio físico es ideal en ese sentido. También podemos efectuar la conversión a través del ejercicio mental: ajedrez, cartas, juegos de mesa y actividades parecidas que no dañan a nadie y que, sin embargo, sirven para aplacar el enfado".$^{28}$ Pero, además podemos transformar la energía negativa en positiva, por ejemplo dedicándonos al arte: escribir un libro, dibujar una pintura, interpretar o componer música, dedicarse a la fotografía, a la danza, escultura, etc. Así, tal vez, y poco a poco, podremos ir disminuyendo nuestros impulsos negativos.

Las Opciones y Decisiones son el último paso para la edificación de nuestra casa filosófica. Aquí el mayor desafío que nos presenta la vida es tomar las mejores decisiones en lugar de las peores. Sin lugar a dudas es una compleja tarea. En rigor, "una filosofía de vida debería proporcionar orientación cuando más se necesita; es decir, debería ayudarnos a tomar las decisiones más difíciles, así como a elegir las opciones óptimas. ${ }^{\prime 29} \mathrm{Al}$ respecto, tal vez sería prudente pensar en la filosofía del cambio de rumbo cuando las cosas no van bien y evaluar varios planes alternativos para superar un problema. En efecto, si la dirección que toman los sucesos nos producen más malestar que

\footnotetext{
Ibídem. Pág. 337.

Ibídem. Pág. 343.

Ibídem, Pág. 344.
} 
bienestar, habría que pensar en proyectos alternativos para cambiar esa situación. Es decir habrá que evaluar otros planes para solucionar el problema. La pregunta que uno debe hacerse es: ¿se puede cambiar de rumbo?, ¿qué otros planes se pueden llevar a cabo? Lo fundamental, entonces, es tomar las mejores decisiones y no las peores.

En resumen, a partir de este sencillo proceso llamado MEDIO podemos comenzar a formular una filosofía de vida, teniendo presente que ésta va a configurarse a partir de las situaciones personales, de las lecturas, de los grupos a los cuales se pertenece, de la reflexión realizada, etc. Sin embargo, hay que dejar en claro que las experiencias de la vida, obviamente no dependen totalmente de nosotros; después de todo, estamos rodeados de millones de seres humanos, donde nos cruzamos e interferimos mutuamente. No obstante, el modo de interpretar aquellas situaciones depende en gran medida de cada persona y de su particular pensamiento de la vida, de sus principios, valores, experiencias, creencias y deberes, en definitiva de su filosofía de vida. Es un trabajo arduo, pero nos pueden ayudar los grandes filósofos y corrientes de pensamiento de todos los tiempos. Como dijo Epicuro: "Vana es la palabra de un filósofo que no cura ningún sufrimiento del hombre. Pues tal como ningún provecho se saca de la medicina que no expulsa las enfermedades del cuerpo, ningún provecho se saca, tampoco, de la filosofía que no expulsa el sufrimiento de la mente." 30

\section{Consideraciones finales sobre filosofía práctica}

todo ser humano se ve enfrentado a situaciones profundas como el amor, la muerte, el sentido de todas las cosas, la supuesta existencia de Dios, etc. Es allí donde aparecen las preguntas filosóficas. Las respuestas vendrán desde la razón, desde el sentimiento, desde la experiencia personal, de las lecturas realizadas, etc. Este breve escrito quisiera ser una introducción a la filosofía práctica: por tanto, pretende seguir una

30 Citado por MARINOFF, Lou. Pregúntale a Platón. Pág. 9. 
dirección: la búsqueda consciente de una filosofía de vida que pueda orientar la existencia cotidiana. Es una tarea difícil, absorbente, pero edificante. Buscando ese objetivo es que hemos seguido el lema socrático "conócete a ti mismo" y así enfrentar la vida con una perspectiva diferente, una visión panorámica, filosófica. Es la búsqueda consciente y consistente de una filosofía práctica, apoyándose en el pensamiento de grandes filósofos, de tradiciones de sabiduría de Oriente o de Occidente, etc. Luego, cada ser humano puede trabajar conscientemente en su propia filosofía de vida, ayudado por pensadores antiguos como contemporáneos. Esta se logra con el esfuerzo individual, a través de la reflexión sobre la experiencia de uno u de otros, también a partir de lecturas, de agudizar los sentidos y el pensamiento, pero también puede lograrse con las reflexiones de los filósofos, poetas, etc. Así progresivamente cada persona podrá ir formando una concepción totalizadora de la existencia, su filosofía de vida. Luego, la propuesta de este escrito es que la filosofía teórica, propia de los especialistas y grandes filósofos, puede complementarse con una filosofía práctica de vida, y esta última es factible para cualquier persona común que abra su mente a esta posibilidad. Si la filosofía teórica surge del estudio riguroso de los libros y textos de los filósofos importantes, la filosofía práctica comienza con el conocimiento de sí mismo, de las otras personas, y de Dios (para un creyente). La filosofía práctica nos enseña a vivir y a transformarnos. Por eso estamos muy de acuerdo con la filósofa española Mónica Cavallé: "una filosofía que no tenga un potencial transformador y liberador, no es una buena filosofía. Es sólo apariencia de conocimiento, pero no un conocimiento real. Una filosofía que sea una fábrica de mediocres ilustrados, y no de mejores seres humanos; de pedantes y no de personas veraces; de intelectuales, y no de sabios; de malabaristas de las palabras y de las ideas, pero no de personas capacitadas para el silencio interior y para la visión que sólo este proporciona, no es filosofía esencial." ${ }^{\prime 11}$ La filosofía esencial es un arte para saber vivir, es sabiduría de vida, y todas las personas

31 Cavallé, Mónica. Op. Cit. Pág. 45. 
necesitamos luces para vivir con más plenitud. Aquí la filosofía no es teoría, se vuelve práctica, un modo de ser, un estilo de vida, una suerte de sanación para el alma. En definitiva, la filosofía práctica o también llamada terapia filosófica, es una corriente de pensamiento que pretende llevar la presencia de la reflexión filosófica a la vida personal y social; en otras palabras, es tratar los problemas cotidianos con filosofía. Según la idea que parece hoy dominante en la calle, la filosofía sería una árida, abstrusa y ardua disciplina intelectual sólo asequible a especialistas y cultivada en las universidades; sus temas parecen alejados de los problemas cotidianos, y el filósofo en el mejor de los casos es visto como un pensador que posee una comprensión más profunda del mundo y del ser humano, sin que esa comprensión tenga efectos transformadores en la vida concreta. En cambio, este nuevo movimiento de filosofía práctica o terapia filosófica, quiere rescatar la antigua concepción originaria de la filosofía como sabiduría vital con poder para sanar al individuo y dar plenitud a su existencia. Aunque el ritmo demasiado acelerado de la vida moderna no nos deja el tiempo para la reflexión serena sobre lo que nos pasa ni sobre el fundamento de nuestras convicciones, expectativas y esperanzas, tal reflexión debería ser una compañera inseparable, porque sólo es verdadera vida humana aquella que se hace lúcida a sí misma y por tanto consciente y libre. La nueva figura del asesor o consejero filosófico se ofrece como una ayuda para aquellas personas que quieren meditar su propia vida concreta para conocerse mejor, desarrollarse y ser mejores personas en el mundo del siglo XXI.

\section{Bibliografía}

BRAVO DONOSO, Nina. Valores Humanos. Por la senda de una ética cotidiana. RIL Editores, Santiago, 2001.

CASTILLO ÁVILA, Francisco. El mal. Una mirada desde la reflexión filosófica. UCSH, Santiago, 2010.

CAVALLÉ Mónica. La sabiduría recobrada. Filosofía como terapia. Ediciones Martínez Roca, Madrid, 2006. 
DELIUS, Christoph y otros. Historia de la filosofía. Desde la antigüedad hasta nuestros días. Ediciones Könemann, Barcelona, 2000.

DEWEY, John. Democracia y Educación. Editorial Losada, Buenos Aires, 1953.

GAARDEN, Jostein. El Mundo de Sofía. Ediciones Siruela, Madrid, 2003.

GARCÍA MORENTE, Manuel. Lecciones preliminares de filosofía. Editorial Losada, Buenos Aires, 2001.

GIANNINI, Humberto. Breve historia de la filosofía. Editorial Universitaria, Santiago, 2003.

GUARDINI Romano. La muerte de Sócrates. Emecé Editores, Buenos Aires, Argentina, 1997.

HESSEN. Johan. Teoría del Conocimiento. Editorial Losada, Buenos Aires, 1968.

JAMES, William. El Pragmatismo. Editorial Américalee, Buenos Aires, 1945.

MARINOFF, Lou. Más Platón y menos Prozac. Ediciones B, Barcelona, 2000. Pregúntale a Platón. Ediciones B, Barcelona, 2003.

El término medio. El ABC de la felicidad. Ediciones B, Barcelona,

2006.

MILLAS, Jorge. Idea de la filosofía, Volumen I y II, Editorial Universitaria, Santiago, 1969.

OYARZÚN, Pablo. El dedo de Diógenes. Dolmen Ediciones, Santiago, 1996. PLATÓN. Diálogos. Ediciones Aguilar, Madrid, 1985.

PLATÓN. Apología de Sócrates. Editorial Universitaria, Santiago, 1983.

YARZA, Iñaki. Historia de la Filosofía Antigua. Ediciones Universidad de Navarra, Pamplona, España, 1992. 